\title{
MINERALOGICAL CLASSIFICATION OF SOUTHERN AFRICAN KIMBERLITES
}

E.M.W. Skinner (De Beers Consolidated Mines Limited, Box 616, C.R. Clement 8300 Kimberley, South Africa)

A fundamental requirement for the mineralogical classification of any suite of rocks is the delineation of valid petrographic limits. For this classi= fication we consider that such linits are embodied in the definition of kimberlite proposed by Clement et al. (this volume). The salient points of this definition are:

i) Kimberlite is a volatile-rich, potassic, ultrabasic, igneous rock which has a distinctively inequigranular texture resulting from the presence of macrocrysts set in an essentially microporphyritic matrix.

ii) The matrix contains as prominent primary phenocrystal and/or groundmass constituents, olivine and several of the following minerals; phlogopite, calcite, serpentine, diopside, monti= cellite, apatite, spinels, perovskite and ilmenite. Other primary minerals may be present in accessory amounts.

iii) The macrocrysts belong almost exclusively to a suite of anhedral, cryptogenic, ferromagnesian minerals which include olivine, phlogopite, picroilmenite, magnesian garnet, chromian diopside and enstatite. 0livine is extremely abundant relative to the other minerals which need not all be present. In addition to macro= crysts smaller grains belonging to the same suite also occur.

Early classifications of Southern African occurrences subdivided kimberlites into two main types, namely, "basaltic" kimberlite and "lamprophyric" or "mica= ceous" kimberlite. These terms have become widely accepted and this sub= division still forms the basis of most recent classifications (eg. Milashev, cited by Frantsesson, 1970). A different approach is used by Mitchel1 (1970) who subdivides kimberlites according to the relative abundances of olivine, phlogopite and carbonate minerals.

We consider that previous classifications are inadequate principally for one or more of the following reasons:

i) Usage of incorrect or misleading terminology.

ii) Failure to take into account the range of essential minerals that may be present in kimberlites.

iii) Failure to discriminate adequately between xenogenic, cryptogenic, metasomatic and primary minerals.

A11 previous subdivisions have in some respect utilized the presence of olivine in kimberlite. This is not surprising as olivine is often the most abundant mineral present. Its abundance is, however, largely independent of the varia= tion in abundance and type of other constituents. Furthermore much of the olivine in kimberlites may have a xenogenic origin and adequate distinction between this olivine and undoubtedly primary olivine cannot be made. Conse= 
quently olivine is of limited use for classification purposes.

The classification presented here is based on the examination of more than 200 Southern African kimberlites. Modal analyses indicate that, in add $i=$ tion to olivine, any one of five other primary minerals may be a major constituent of kimberlite. These minerals are PHLOGOPITE, CALCITE, SERPENTINE, DIOPSIDE and MONTICELLITE. Accordingly we propose the recogni= tion of five basic subdivisions of kimberlite, named after whichever one of these five minerals is volumetrically most abundant (eg. diopside kimberlite, monticellite kimberlite, etc.) Further subdivision can be made if one (or more) of these minerals is present in sufficient abundance to qualify as a characterizing accessory or modifier (eg. diopside-phlogopite kimberlite). We accept the possibility that, in addition to the five minerals listed above, some other mineral may occur as a major constituent of kimberlite. In this event our primary subdivision could be extended.

In the kimberlites examined only one other mineral has been found to occasionally occur in sufficient abundance to qualify as a modifier. This mineral is apatite. A problem exists with respect to opaque oxides which are some= times volumetrically abundant in kimberlites. Since individual opaque minerals cannot be identified during point counting in transmitted iight the use of opaque oxides for classification purposes is limited. However, kimberlites containing abundant opaque. oxides could be referred to as opaqueoxide-rich. Modal analyses of 12 kimberlites are presented in table I. These analyses have been selected to illustrate the application of the proposed classification to kimberlites exhibiting variable mineralogies.

Any mineralogical classification of kimberlites will often be hindered by alteration. This alteration reflects deuteric and/or metasomatic processes which cannot always be distinguished from each other. The effects of deuteric alteration are evident to some degree in many kimberlites but for the most part do not cause serious problems with respect to classification. Extensive meta= somatic alteration introduces a subjective element into classification as interpretive assessment of the nature of the original minerals, based on relict mineralogy and texture, becomes necessary. Extreme alteration such as that commonly reflected by highly metasomatized and weathered kimberlites (the latter containing considerable clay material) can render reliable classification impossible. In such cases we suggest that altered kimberlites be named according to the dominant alteration process as indicated by the alteration products present (eq. carbonatized kimberlite).

We consider that, as it is based on quantitative modal analyses, our proposed classification provides a practical basis for subdividing kimberlites in terms of mineral content. Hopefully it will provide a broader base for comparing kimberlites of divergent and like mineralogy and for comparing kimberlites with other rock types.

REFERENCES :

Frantsesson E.V. (1970), The Petrology of the Kimberlites. Trans. by D.A. Brown. Aust. Nat. Univ., Canberra.

Mitche11 R.H., (1970), Jour. Geol. 78, 686-704. 




